\title{
Central catheter indicators in pediatrics: evidence for the care improvement in a Brazilian pediatric hospital.
}

\author{
Reche TSS, Lopes AR, Pirolo P, Lima I, Fonseca S. Children's Hospital Sabará. São Paulo - SP - Brazil.
}

\section{INTRODUCTION}

Nursing care given to patients using central venous access competes with practices related to patient safety.

\section{Nurse care Infusion Therapy - Children's Hospital}

\&. Peripheral Central Insertion Catheter (PICC)

if Central Venous Catheter

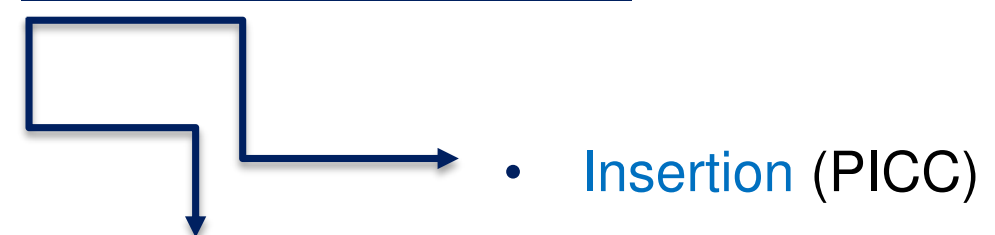

- Maintenance (dressings and administration of drugs) - PICC e CVC

\section{Measurement of activities Indicators}

iTo monitor and evaluate the events that affect users, workers, and organizations, pointing out processes and organizational results, aiming at the excellence of care.

\section{Question Research:}

How is the quality of nursing care about the central intravenous therapy at a private children's hospital of São Paulo State?

\section{OBJECTIVE}

The objective of this study is to report the results obtained by the management of central venous catheters indicators in a pediatric non intensive care unit.
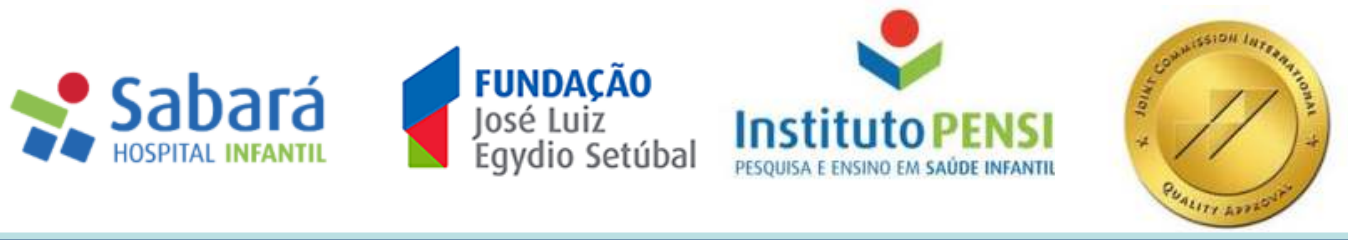

METHOD
- Quantitative, retrospective and descriptive study.
- Survey quality indicators - central venous catheters in
pediatrics.
- 2017 (Jan - Dec).
- 70 beds of Inpatient room.

Number of bloodstream infections related to the CVC IR X1000 Patient-day number with central venous catheter in IR

Number loss of central catheters $\mathrm{X} 100$ Number patients-day with central catheters

\section{RESULTS}

- 5738 admissions of pediatric patients.

- average occupancy rate of $86 \%$.

- The patient/day number - 23.038/2017.

- The patient/day number central catheter - 3.531/2017.

- Rate Catheter loss notification $-0.19 \%(n=7)$.

- Density of infection related to central catheter $-0.11 \%(n=4)$.

\section{CONCLUSION}

if Quality of the care given to the central catheters management to the pediatric patient is reflected by the low rates of complications monitored by the care indicators.

\&. Pediatric non intensive care unit (inpatient room) reflects the concern to put the patient in the forefront by competing with evidence-based best practices.

if The use of advanced techniques of central catheter passage (exclusively surgical center) with the implantation of a catheter passing team in 2017 has contributed to reach the pediatric nursing excellence assistance performed at the institution.

Patient/day number (Total of 23.038 cases)

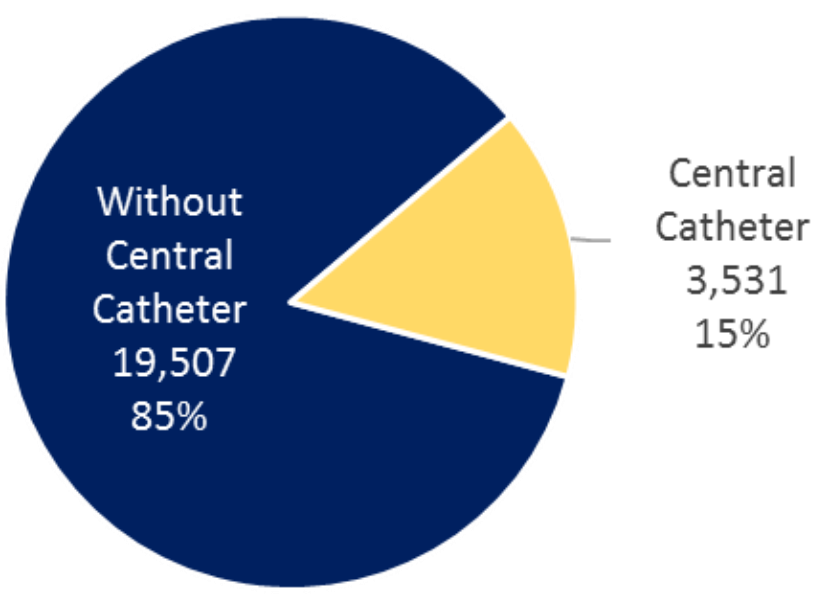

3.531 The patient/day number central catheter

11 Issues $(0,3 \%)$ :

4 Blood Stream Infection (0,11\%)

7 Catheter Loss $(0,19 \%)$ :
3 Obstruction
2 Exteriorization
1 Thrombus

1 Extravasation

1. Brazil. National Health Surveillance Agency. Diagnostic Criteria for Health Care - Related Infections / National Health Surveillance Agency. Brasília: Anvisa, 2017. 2. Souza AEBR, Oliveira JLC, Dias DC, Nicola AL. Quality of nursing therapy intravenous therapy: analysis by indicators. Rev. Cogitare Enferm. $2014 \mathrm{jul} / \mathrm{set} ; 19$ (3): $521-7$ 